\title{
Retrieval inhibition from part-set cuing: A persisting enigma in memory research
}

\author{
RAYMOND S. NICKERSON \\ Bolt Beranek and Newman Inc., Cambridge, Massachusetts
}

\begin{abstract}
When people are asked to recall words from a list they have just studied or to produce as many items as possible from a well-known category (e.g., states of the United States), having available a subset of the items as cues often does not facilitate retrieval of the remaining items and sometimes inhibits it. The finding has been obtained many times with a variety of experimental tasks including recall from categorized and noncategorized lists and retrieval from very long-term memory. This paper reviews the studies that have yielded the effect, and considers several explanations of it that have been proposed. None of these explanations is viewed to be entirely adequate and compelling.
\end{abstract}

When people are asked to recall words from a list they have just studied and are given a subset of the words on that list as cues, they typically do no better, and often do more poorly, at recalling the remaining items on the list than do people who are asked to recall the words without the benefit of cues. Similarly, when people are asked to list as many items as possible from some set that is assumed to be stored more or less permanently in long-term memory (e.g., names of states of the United States), presentation of a subset of the items as retrieval cues typically is not helpful, and may have an inhibitory effect on production of the remaining items. Such findings have been viewed as surprising because they seem to be inconsistent with the widely accepted idea that memory is associative and that the retrieval of items from memory can be facilitated by the activation of associated items. And indeed, facilitation has often been found. For example, when people have been given lists to study that are composed of several words drawn from each of several semantic categories (e.g., animals, countries, occupations), presentation of the category names as recall cues has typically been beneficial. Even in this case, however, certain types of inhibitory effects have sometimes been obtained.

A better understanding is needed, both of the conditions under which facilitation or inhibition occurs, and of why either occurs when it does. The purpose of this paper is to review studies of word recall, or word retrieval, with these goals in mind. The review focuses on studies in which inhibition, or lack of facilitation, has been found; studies that have shown facilitation are considered insofar as they seem to help delimit the conditions under which inhibitory or nonfacilitatory effects are likely to be obtained.

The experimental tasks used in the studies reviewed fall

This work was sponsored, in part, by Contract $400-80-0031$ with the National Institute of Education. The author is grateful to John Brown, Henry Roediger, and Norm Slamecka for helpful comments on a draft of the manuscript. The author's mailing address is: Bolt Beranek and Newman Inc., 10 Moulton Street, Cambridge, MA 02238. into two major categories: those involving the recall of words from a list that was recently studied, and those requiring the retrieval of words from relatively permanent memory. Another useful distinction is the distinction between categorized and noncategorized word lists. In some of the recall studies considered, the word lists were composed of a few words from each of several conceptual categories; in others, the lists were not intentionally given any categorical structure.

Experiments involving recall from noncategorized lists are considered first. Consideration of cued recall from categorized lists focuses first on experiments in which category names have been used as recall cues and then on those that have used category instances, possibly in addition to category names. Then some experiments are noted in which the task was to retrieve words from longterm memory. Finally, several explanations that have been proposed of why cues are sometimes inhibitory, or at least not facilitative, are reviewed.

Much of the literature that is reviewed refers to "partlist" cuing, and appropriately so, inasmuch as the cues are items that appeared on the list the subject was asked to recall. In other cases the term "part-set" cuing is used because the cues are from a set (e.g., category) to which the items to be retrieved belong, but did not necessarily appear on a list to be learned for purposes of the experiment. In this paper, the term "part-set" is used throughout because of its greater generality and the fact that it includes "part list" as a special case.

\section{Part-Set Cuing with Noncategorized Lists}

Several experiments have been done in which subjects are given a list of words to study and then are asked to recall as many as possible of the words on the list, sometimes with and sometimes without the benefit of a subset of the list items as recall cues. The question of interest has been whether having a subset of the items on the list available during, or just prior to, the time of recall would affect recall of the remaining items. 


\section{The Basic Finding of an Inhibitory Effect}

In 1968, Slamecka reported a finding that has served as the point of departure for a large percentage of the studies reviewed in this paper. Six experiments were performed in which subjects listened to the reading (twice) of 30-item lists and then attempted to recall the items. Experimental subjects were given a written subset of the items as cues and were instructed to recall the remaining items. Controls were asked to recall as many of the items as possible from the entire list without the aid of cues. Rarity of the words constituting a list was varied, as was the strength of between-word associations. The number of cue words provided to the experimental subjects ranged from 5 to 29. (In one of the experiments-Experiment IV-the study list was composed of 6 words from each of five categories. This experiment will be discussed subsequently in the context of the discussion of recall of categorized lists.) Subjects who were given the recall cues recalled a smaller proportion of the noncue items than did the controls, independently of the composition of the lists-and in particular of the strength of interitem associations-and of the number of words presented as cues.

In the two final experiments of his 1968 study, Slamecka tested the hypothesis that the cues were inhibiting because experimental subjects had to scan them before beginning to recall, whereas controls were able to start recalling straightaway. The possibility that the interpolated cuescanning task interfered with the recall from short-term memory of the later items on the list got some support from the fact that experimental subjects recalled fewer terminal items than did controls. To check this possibility, Slamecka had all subjects recall as many words as possible during $4 \mathrm{~min}$, after which experimentals were given a subset of the unrecalled items and were asked to recall the remainder, whereas controls were asked to recall as many additional items as they could without cues. In the final experiment, the conventional design was used, except that the controls were given a filler task while the experimental subjects were scanning their cues, to ensure that the former did not get a head start at recall. In these cases, the inhibiting effect of cuing was not found. Slamecka conjectured that the inhibiting effect obtained in his first four experiments was attributable to a "tangential procedural artifact which apparently influenced short-term memory differentially between the groups" (p. 510). He noted, however, that even when this factor was controlled, the presentation of cues failed to have a beneficial effect. This fact was taken as evidence that items are represented in memory independently and that the various types of associative or categorical clustering that are sometimes obtained in recall are the results of application of a recall plan, based on the subject's awareness of list structure, to the independently stored items.

In a follow-up study, Slamecka (1969) tested the possibility that the earlier failure to find a facilitative effect of cues was unique to the situation in which the subject has only a single chance to recall the list. Subjects were given three alternative study and test trials with the same 30 words presented in a fixed order. On the third test, the experimental subjects were given 16 of the words as cues. In a second experiment, subjects were informed of the nature of the final test trial at the beginning of the experiment, so they would be encouraged to take full advantage of iteritem associations in order to facilitate recall. In neither experiment was the effect of cues facilitative; and in the second one, it was slightly inhibitory. An analysis of the number of noncue words recalled on Trial 2 but not on Trial 3 (words lost) and of those recalled on Trial 3 but not on Trial 2 (words gained) showed that experimental subjects lost more words than controls, whereas both groups gained about the same number. This finding, coupled with the fact that recall in these experiments was always delayed $30 \mathrm{sec}$ following list presentation, was taken as evidence against the earlier conclusion (Slamecka, 1968) that the inhibiting effect of cues was a short-term memory effect.

An inhibitory effect similar to that found by Slamecka (1968) was obtained by Roediger, Stellon, and Tulving (1977). After listening twice to 48 semantically unrelated words, some subjects were given either 16 or 32 of the original items and were asked to recall the remaining items. Uncued controls recalled more of the 16 items that were not on either cue list than did the experimental groups.

In a second experiment, Roediger et al. (1977) provided some subjects with a subset of the list items as cues, some other subjects with extralist items (items that had not been on the original list) as cues, and still others with a mix of list and extralist cues. Half of the subjects who received only list cues had them available during recall and were told to recall only noncue items. The other half were shown the cues before attempting recall but did not have them available at the time of recall; they were asked to recall all the words on the original list, including the cues. Subjects who received extralist cues or a mix of extralist and list cues also were asked to recall as many as possible of the original items. Both list and extralist cues had an inhibitory effect on the recall of noncue items; however, the effect of extralist cues was not as large as that of list cues. Moreover, subjects were likely to recall more noncue items if they studied the cues and then attempted to recall all the items on the original list than if they had the cues before them at recall time and attempted to recall only noncue items. It is important to note that in this experiment the inhibitory effects persisted across a relatively long $(10-\mathrm{min})$ testing period and therefore were not due to inadequate recall time.

\section{Postrecall Cuing}

In some of Slamecka's (1968) experiments and those of Roediger et al. (1977), subjects were given the cues before attempting recall, or not at all. Allen (1969) gave subjects list items as cues only after they had recalled as 
many words as they could without the aid of cues. (A similar procedure was used by Slamecka in the fifth of the six experiments in his 1968 study.) Some of the cues Allen presented were items the subjects had already produced; others were items they had not recalled. Cues were facilitative with lists composed of pairs of semantically related words but not with lists of unrelated words. Unrecalled items were more effective as cues than were items that had already been recalled.

It is not surprising that cues were not inhibitory when they were presented only after subjects had recalled all the items they could recall in the absence of cues; items whose recall would have been inhibited by the presentation of cues should have been recalled by the time the cues were presented. The finding that cues were not facilitative when presented after subjects had recalled what they could from semantically unrelated lists without cues reinforced Slamecka's finding of a nonfacilitative effect.

\section{Facilitation With Prerecall Cuing}

That part-set cues can be facilitative even with lists of unrelated words was demonstrated by Basden (1973), who began with the assumption that facilitation should not be expected unless the list is organized, the cues are appropriate to this organization, and subjects are unable to recall all the organizational units spontaneously. Basden's objective was to demonstrate that an unstructured list would become organized if a subject spent sufficient time learning it, and that judiciously selected items could serve as effective cues with such a list.

Subjects learned 30 unrelated words to a recall criterion of 21 correct responses. After reaching criterion, they performed another list-learning task with a different set of words for seven study-recall trials. Then subjects again tried to recall the words from the original list. As cues, each experimental subject was given the words that occupied the odd-numbered Serial Positions 1-19 on that subject's final recall attempt in the original list-learning task. The rational for selecting these items as cues was that it would ensure the presence of at least one cue from each of the organizational units in terms of which items were represented in the subjects' memory, assuming that members of a given unit are recalled consecutively. Cued subjects in this experiment did recall more critical noncue words than did uncued subjects.

In a similar experiment, Blake and Okada (1973) gave subjects 10 study-test trials with lists of 16 words. Following the 10th trial with the original list, subjects had 10 study-test trials with a second list as an interpolated retroactive-interference task, after which they were asked to recall the original list. Under these conditions, provision of half the items from the original list as cues also facilitated recall of the remaining items. This result was taken as evidence that cues will be facilitative if exposure to items on a list is sufficient to provide an opportunity for higher order structures to be developed.

\section{Summary of Findings With Part-Set Cuing With Noncategorized Lists}

- When subjects have been given some of the items from a noncategorized study list as recall cues, they typically have done no better than controls in recalling the remaining items, and sometimes have done worse.

- List cues have had less of an inhibiting effect on the recall of noncued items when subjects have first studied the cues and then attempted to produce all the items, including cues, than when the cues have been present during recall and subjects have attempted to produce only noncue items.

- When items that have not appeared on the original list have been given as cues, they too have sometimes had an inhibiting effect on the recall of noncue items, but the effect has not been as great as when list items have been used as cues.

- When list cues have been given after subjects have recalled all the items they could without the benefit of cues, they have not facilitated the recall of additional items when the items on the list have not been semantically related.

- List cues have been facilitative when subjects have learned a list to a high, but less-than-perfect, criterion or the learning has been followed by a proactive-interference task.

\section{CATEGORY CUING}

Many of the studies of effects of cues on word recall have used categorized word lists. In some cases, the categorical composition of a list has been made apparent at the time of learning either by the blocked organization of the list or by the instructions to the subjects. In other cases, the word order has been such as to obscure the categorical composition and subjects have not been informed of it until just before the recall test, if at all. Recall cues have sometimes been category names, sometimes instances of category members from the lists, and sometimes both. In this section, only experiments in which the cues have been category names are reviewed; experiments in which category-instance cues have been used are considered in the following section.

\section{Facilitative Effects From Category Cuing}

Among the first studies in which category names were used as cues was one by Tulving and Pearlstone (1966). All nine possible combinations of list lengths of 12, 24, or 48 and number of words per category of 1, 2, or 4 were used. The lists, blocked by category, were presented auditorily; the name of each category was given just before the items in that category. Subjects were informed of the number of categories and number of words per category that would be in the list they were to learn.

Use of the category names as cues facilitated recall, more so when the cues were given at the beginning of the recall task than when they were presented after sub- 
jects had recalled what they could without cues. Apparently, the provision of category names at recall time facilitated access to information that was in memory but inaccessible without the cues. This finding was the basis of the now familiar distinction that Tulving and Pearlstone (1966) made between the availability of information in memory and its accessibility, and led to the subsequent distinction between "trace-dependent" and "cuedependent" forgetting (Tulving \& Madigan, 1970).

Another important aspect of Tulving and Pearlstone's (1966) results is that the provision of category names as cues increased the number of categories from which at least one word was recalled, but did not affect the number of words recalled per recalled category. ${ }^{1}$ This suggests that what the category names provide access to are the categories per se, and that once one has accessed a category, the number of words one produces from that category is independent of whether or not the category access was the consequence of an experimenter-provided cue.

Since Tulving and Pearlstone's (1966) study, several other investigators have demonstrated that category labels can be effective recall cues under a variety of conditions. Pollio and Gerow (1968) got facilitation from category names even when the words were presented in random order and subjects were told of the categorical structure just before the recall test. Dong and Kintsch (1968) had subjects sort noncategorized words into categories and label each category; the labels then served as effective recall cues for items in the categories. Bellezza and Hartwell (1981, Experiment 2) did a similar experiment and obtained similar results.

The results of these experiments demonstrate clearly that category names and category members can be effective cues to the recall of members of the cued categories from a studied list. As Bellezza and Hartwell (1981) pointed out, the effectiveness of this type of cuing can be demonstrated only when the number of subjective units exceeds what subjects are able to retrieve spontaneously. We should note too that in each of the studies mentioned in this section either all the categories (or all the categories from which subjects failed to recall spontaneously) were cued or none of them was. Therefore, these studies do not speak to the question of whether cuing a subset of the categories might have an inhibitory effect on the accessibility of the remaining categories. We turn now to several studies in which only a subset of categories was cued.

\section{Partial Category Cuing}

Dong (1972) gave subjects 100 words from 10 categories and tested recall under three conditions: noncued (recall from the entire original list without cues); cued (recall from the entire list, given the names of the 10 categories); and partially cued (recall from a single named category). More items were recalled per category under the partially cued condition than under either of the other conditions. Performance under the other two conditions did not differ, but this might have been due to a ceiling effect, inasmuch as the mean number of categories recalled by the uncued subjects was 9.8 . This experiment also did not speak to the issue of the effect of cuing of some categories on recall from other categories because there was no condition in which subjects had to recall from all categories only some of which were cued.

In another study of category cuing, Parker and Warren (1974) had subjects listen to lists of 40 words organized as 202 -word categories. The category name was always announced just before the two items of that category were presented. Experimental subjects were given the names of 10 of the categories to read just prior to attempting to recall the items. They also were told that these category names would be available to aid their recall but that they should attempt to recall as many items as they could before looking again at the category names.

Cuing had a generally facilitative effect, and, as in Tulving and Pearlstone's (1966) study, the larger number of words produced by the experimental subjects was a consequence of the larger number of recalled categories; the mean number of words recalled per recalled category was about the same as that for controls. Of greatest interest vis-à-vis inhibiting effects of cues is the fact that experimental subjects recalled words from fewer uncued categories than did the controls. Representation of category cues in this case seems to have inhibited the recall of uncued categories per se. Parker and Warren (1974) concluded that the presentation of category names as recall cues facilitates the recall of items in the cued categories but inhibits the recall of other categories.

To follow up Parker and Warren's (1974) results, Roediger (1978) did three experiments with categorized lists. In the first, he gave subjects blocked lists composed of eight words from each of eight categories. In one of four conditions, subjects recalled as many of the list words as they could without cues. In a second condition, all the category names were given as cues. In a third, names of four of the categories were given, but subjects were asked to recall from all categories. In a fourth condition, names of four of the categories were given and subjects were to recall words only from the remaining categories.

Subjects who performed under the third condition recalled fewer critical items (items from the four categories not cued in the third and fourth conditions) than did subjects in any of the other three groups. The average number of words recalled per recalled category was essentially the same for all four groups, but the third group recalled words from fewer of the critical categories than did the others. These subjects did recall words from more cued categories than did those who were given no cues. Thus, as in the Parker and Warren (1974) study, category cues facilitated recall from the cued categories but inhibited recall from the uncued categories.

Roediger (1978) considered the possibility that the poorer recall from the uncued categories by his third group resulted from subjects' spending more time recalling words from the cued categories to the neglect of the uncued categories. Support for this notion came from the 
fact that most of the cumulative recall curves had not reached asymptote by the end of the 7.5-min recall period. Roediger speculated that a similar explanation might pertain to Parker and Warren's (1974) results. To check this possibility, he gave subjects 50 words ( 10 categories, 5 words per category), and allowed $10 \mathrm{~min}$ for recall from the entire list, given zero, two, four, or seven category names as cues.

In general, the larger the number of category names provided as cues, the more poorly subjects did in recalling items from the three uncued categories. Roediger dismissed the lack-of-time explanation of this result on the grounds that the cumulative recall curves appeared to be close to asymptote by the end of the $10 \mathrm{~min}$. As in the first experiment, the groups differed primarily with respect to a number of critical categories recalled: This variable decreased as the number of category cues increased, but the mean number of items recalled per recalled category was almost identical for the four groups. Roediger noted that in these experiments category cues facilitated recall from cued categories and inhibited recall from uncued categories in a roughly complementary fashion. Considering both cued and uncued categories, the total number of words recalled was relatively constant across conditions.

In a third experiment, Roediger (1978) gave subjects a list of 100 categorized words, 5 from each of 20 categories. Before attempting to recall these words, control subjects were given one of three different tasks: to read a brief passage, to name states of the United States, or to recall words from a list of 50 unrelated words that had been read to all subjects. Control subjects recalled the words on the categorized word list without cues at about the same level, irrespective of the nature of their interpolated task.

For one of two experimental groups, the interpolated task was to recall from 10 specified categories represented on the list. This group was then asked to recall the words from the remaining categories without category cues. These subjects did more poorly on recalling critical items than did the controls. As in the earlier experiments, the decrement could be accounted for primarily in terms of category recall as opposed to the recall of items within recalled categories.

A second experimental group in Experiment 3 was treated exactly like the first through the interpolated task; however, when this group was asked later to recall the words from the remaining (critical) categories, it was given the names of these categories as well. These subjects did much better than the other experimentals and the controls at recalling critical items. Roediger took this as evidence that recall interference reduces primarily the accessibility of items rather than their availability (Tulving \& Pearlstone, 1966).

Indeed, all of the studies that have been considered so far have been consistent with the idea that the inhibitory effect of category cuing is primarily that of reducing the number of uncued categories from which words are recalled, rather than that of reducing the number of words recalled per recalled category. Stated in these terms, the inhibitory effect found with categorized lists appears to be similar to the one found with noncategorized lists, except that the inhibition occurs at a higher level of organization (Parker \& Warren, 1974): With categorized lists, the recall of uncued categories is inhibited, whereas with noncategorized lists, what is inhibited is the recall of words. If one thinks of each of the words in a noncategorized list as representing a different category, then one can view the inhibition of word recall as a special case of the inhibition of category recall.

\section{Must Category Instances be Recalled for Category Names to Have an Inhibitory Effect?}

A question that this line of thinking raises is the following one: Does the inhibitory effect of presenting a category name as a cue depend on how many words are recalled from that category, or indeed on whether any are? In one experiment addressed to this question, Roediger and Schmidt (1980) showed that recalling items from a specified subset of the categories represented on a study list inhibited subsequent recall of items from other categories to the same degree whether the initially recalled categories contained three items or nine items each, even though subjects did in fact recall more items per category in the latter case. From this, they concluded that what determines the degree of inhibition caused by the partial recall of categorized lists is not the number of items recalled but the number of categories.

In at least one study (Roediger \& Tulving, 1979), telling subjects at the time of recall to ignore specified categories that had been studied not only failed to improve recall of the remaining categories but even impaired it slightly; again, the impairment was more with respect to the recall of categories than with respect to the recall of items from recalled categories. Apparently, the act of processing the names of the categories specified as forgettable was enough to produce the inhibitory effect. Roediger and Schmidt (1980) did not get impairment with a somewhat similar condition; however, in their experiment the categories from which subjects were to recall were cued, whereas in the Roediger and Tulving experiment they were not. Inasmuch as the inhibiting effect of category cuing is primarily on category recall, as opposed to item recall, such inhibition could not occur with the Roediger and Schmidt design.

Another aspect of Roediger and Tulving's (1979) study that deserves comment is the fact that similar results were obtained whether categories were defined by semantic relationships or by the initial letters of the words. Lists were composed of eight words from each of eight semantic categories. When presented (auditorily) for study, the words were blocked by category, and the category name was pronounced just prior to the presentation of each block. All the words in the list began with one of eight 
letters. Each of the words within any given category began with a different one of eight letters. Thus, "words beginning with A" defined a set of eight words, one from each of the semantic categories. Subjects were not told in advance of the possibility of reorganizing the lists in terms of initial letters. At the time of recall, some subjects were given the names of four categories in one experiment and of two or six in another, and were told to recall items only from the remaining categories. Other subjects were given four (or two or six) letters and were told to recall only items not beginning with those letters. Control subjects tried to recall the entire list.

On the basis of results of other studies that had shown that, following presentation of words grouped by category, category names are effective recall cues, whereas initial letters are not (Lauer, 1974; Lauer \& Battig, 1972), Roediger and Tulving expected that category names woud be more effective than initial letters as identifiers of material that subjects could ignore during recall. In fact, instructing subjects to ignore some of the items had a slightly inhibitory effect on recall of the remaining items, and of about the same amount for both types of exclusion cues.

\section{Inhibition from Preceding Recall}

In the experiments considered so far that have obtained clear evidence of inhibitory effects of category cuing, the paradigm has involved having subjects study a categorized list and then giving them a subset of the category names as cues at recall time. Another paradigm that has produced evidence of inhibition involves having subjects study a list composed of words drawn from each of several categories and then asking them to recall the words from each category as its name is given in turn. The typical finding has been that the number of words recalled per category falls off as the position of the category cue increases (Dong, 1972, Experiment 2; Roediger, 1973; Roediger \& Schmidt, 1980; Smith, 1971, 1973; Smith, D'Agostino \& Reid, 1970).

That the act of recalling some items can impair the subsequent recall of other items independently of any input serial-position effects has been shown by Roediger and Schmidt (1980) for both categorized and paired-associate lists. When subjects had to recall category members, given the category name as a recall cue, performance dropped off with the ordinal position of the category cue at the time of the recall test. Similarly, when the first member of each pair of associated words was used as a cue for the recall of the other member of the pair, cued recall decreased as the ordinal position of the cue increased. These results were independent of the order in which the items had initially been presented. The latter finding is similar to an earlier one by Tulving and Arbuckle (1963). In that case, each pair of associates was composed of a single digit and a single word. At recall time, subjects were given the digits in counterbalanced order and were asked to respond with the associated words. Subjects were better at producing the appropriate words in response to the first few digits than to the last few.

\section{Summary of Findings With Category Cuing}

- Presentation, as recall cues, of the names of all the categories represented in a categorized word list typically has facilitated recall. This result has been obtained when the words have been blocked by category at presentation and sometimes when the words have been presented in random order. It has also been obtained when the category cues have been given only just before recall as well as when they have been given before the initial list presentation.

- Presentation of the names of a subset of the categories represented on a categorized word list also has typically facilitated recall overall: Subjects who have received such cues have recalled more words in total than have those who have not received them.

- Facilitation from category cuing has been due primarily to the fact that subjects who have received a partial set of category names as cues have tended to recall items from a larger number of categories than have those who have not received cues.

- When subjects have been asked to recall words from only a specified subset of the categories represented on a list, they have tended to recall more names from those categories than have subjects who have been asked to recall as many items as they could on the list.

- Presentation of the names of a subset of the categories represented on a list has typically not facilitated the recall of items from uncued categories and sometimes has inhibited it. This has been true not only when subjects have had to recall from both cued and uncued categories, but also when they have been told to ignore the cued categories and to recall only from the others.

- Inhibition from category cuing has typically been due to a decrease in the number of uncued categories from which words are recalled rather than to a decrease in the number of words recalled per recalled category.

- The extent to which recall from uncued categories has been inhibited has increased, in some cases, with the number of categories cued, but has been relatively independent of the number of words recalled from each cued category.

- When subjects have been presented sequentially with all the names of several categories that are equally represented on a study list and have been asked to recall items from each category in turn, the number of words recalled per category has decreased as the position of the category in the recall sequence has increased.

\section{CUING WITH CATEGORY INSTANCES}

Several experiments have been done with categorized lists in which cues were category instances rather than the names of categories. In some cases, both category names and category instances have been used. Both types of experiments will be considered in this section.

\section{Cuing With Category Instances From the List}

Wood (1969) gave subjects either three or five alternating study and recall trials with 54-item lists composed 
of 3 words from each of 18 categories. Following the final recall trial, half of the subjects were given 18 cue words, 1 from each category, and were asked to try once more to recall as many of the list items as possible. The remaining subjects were also asked to try to recall the words again, but were given no cues. Presentation of the cue words facilitated recall by subjects for whom the study lists had been blocked by category, but not by those for whom the study lists had been scrambled with respect to category.

Wood's (1969) experiment was similar to Allen's (1969) in that subjects were given cues only after they had recalled as many words as they could in the absence of cues, and consequently the only inhibitory effect it was possible for the cues to have was on those items that were not recalled before the cues were presented. The facilitative effect that the cues had could be accounted for almost entirely in terms of additional categories recalled.

Another study showing facilitation of category recall was done by Hudson and Austin (1970). Subjects listened to lists composed of three words from each of 10 familiar categories, with the order of presentation randomized with respect to category. After a single hearing, subjects recalled words from more categories if they were given either category names or one instance from each category as recall cues than if they were given no cues; however, neither type of cue increased the probability of the recall of words within a category, given that at least one instance of the category was recalled.

Reardon, Polzella, and Brown (1975) worked with subject-defined categories. They had subjects sort 84 words into 28 groups of 3 words each and then attempt to recall the words after studying them in their grouped arrangement. At recall time, some subjects were given 2 words from each of 24 of the groupings as cues. Others were given 24 pairs of words arranged such that the items of a pair came from different groups. Four word groups, for which no cues were presented, served as the baseline (uncued) condition. Both cue arrangements facilitated recall, but that in which both items of a pair of cues came from the same word group was the more effective arrangement of the two.

In a somewhat similar experiment, Bellezza and Hartwell (1981, Experiment 1) had subjects sort 75 words into 15 groups of 5 words on the basis of related meaning. When, in a subsequent recall task, a subject failed to recall any new words over a 1-min period, the experimenter began to provide cues at 30 -sec intervals, each cue being a word from a subject-defined group from which no words had yet been recalled. Fifty-seven percent of the remaining words were recalled under these conditions. In another experiment in the same study, subjects studied preorganized lists of 60 words ( 125 -word categories). The effect of presenting group members as cues following free recall was not as great as that with the subject-defined categories, but was still positive. Items recalled in response to a cue were almost always from the same category as the cue.
The results of these studies are consistent with the idea that a category instance can serve the same cue function and have a similar effect as a category name. It is likely to increase the probability that items will be recalled from the cued category, provided that the categorical structure of the list is known to the subjects and the number of categories is large enough that subjects are unlikely to recall all of them in the absence of cues. There is also some evidence that the stronger the association between a word and a category, the more effectively that word will function as a cue to that category (Hudson \& Davis, 1972; Nelson, McEvoy, \& Friedrich, 1982).

In all of the experiments noted in this section, either all categories were cued by instances, or none was. They do not speak, therefore, to the question of whether the presentation of instance cues for some categories would have an inhibitory effect on uncued categories. However, inasmuch as instances seem to function very much like category names, it seems reasonable to assume that they would.

\section{A Result That Looks Like Inhibition But May Not Be}

Lewis (1971) reported a finding that is of particular interest because it illustrates an important subtlety in the interpretation of certain types of results. Lists were composed of seven words from each of six categories, and one item from each category was presented as a cue at recall time. Study lists were blocked by category for some subjects and were scrambled for others. Cues were found to be facilitative if the items had been blocked by category when originally presented, but not if the items had been presented in scrambled order. In the latter case, providing instances of the categories at recall increased the number of categories recalled and decreased the mean number of words recalled per recalled category. The reduction in number of words recalled per recalled category seems like an inhibitory effect. It is worth noting, therefore, that this result could be obtained in the absence of any inhibition. It should be noted too that Lewis did not refer to the result as evidence of inhibition.

Suppose that, following the study of the original list, all the categories are not equally well represented in memory and that the probability that one will access a category at all increases with the number of words from that category that are represented. In the absence of cuing, then, one would expect subjects to recall words from the most strongly represented categories. For the sake of the argument, assume that, following study, six words from each of three categories and only two words from the remaining three are represented in memory. And suppose that, in the absence of category-instance cues, subjects would recall only the words from the three categories with the six items each. These subjects would recall only three categories but six items per recalled category. Now suppose that, with the cues, the same subjects would recall these items plus two items from each of the remaining categories. Then, the subjects would recall items from all 
six categories, but only four items, on the average, per recalled category. Clearly, this should not be considered an inhibitory effect, inasmuch as the subjects would have recalled everything in the latter case that they did in the former, plus a few additional items. If this had occurred, subjects would have recalled more items, in total, with the cues than without them. In Lewis's (1971) study, there was a small but not significant difference in the total number of items recalled; the difference was large enough, however, to accommodate an effect of the sort described.

The point is that, when cuing produces an increase in the number of categories recalled and a decrease in the average number of items recalled per recalled category, the latter result is not necessarily evidence of inhibition of recall of items within categories. It is exactly what one would expect if the number of items recalled from the categories that would not have been represented in the absence of cuing is less than the number recalled from categories that would have been represented without the aid of cues. The fact that the average number of items recalled per recalled category has typically not decreased when cuing has produced an increase in the number of categories recalled is strongly suggestive evidence that the effect of the cues is primarily that of increasing the accessibility of the categories, and that item accessibility is dependent on category accessibility and is indifferent to how the category itself was accessed.

Characterization of this evidence as suggestive, rather than conclusive, is prompted by two observations. First, one way in which the average number of items recalled per recalled category could remain constant when the number of recalled categories increases with cuing would be for the cues to have the dual effect of (1) increasing the number of items recalled from the categories that would have been represented even without the cuing, and (2) adding some categories from which fewer than the average number of items are recalled. These two effects could offset each other, so the average number of items recalled per recalled category could remain the same. Second, what has been taken as evidence that the number of items recalled per recalled category has not changed has typically been the failure to obtain a statistically significant difference in this variable under the conditions of interest, so the conclusion that there is no difference is based on acceptance of the null hypothesis, and the chances of a Type II error should not be overlooked. Given the magnitude of the effect that one could reasonably expect to obtain if recall from the categories added by the cuing (which tend to be few) were slightly less efficient than recall from the categories that would have been recalled without cuing, it would take a very sensitive experiment to demonstrate it.

\section{Varying the Number of Instance Cues per Category}

If category-instance cues have their facilitative effect exclusively by making the categories they represent more accessible, then there is little reason to expect that several instances from the same category would be any more facilitative than a single one, assuming that one instance is enough to identify a category. To the contrary, the results from experiments on part-set cuing with noncategorized lists might lead one to expect that increasing the number of instance cues in a given category would have an inhibitory effect on the recall of the remaining items in that category. Such an extrapolation makes sense if one thinks of those items from a study list that fall within a given category as composing a list within a list; from this perspective, one would not be surprised to see repeated at the level of the sublist the results that have been obtained with the unstructured lists. On the other hand, the within-category items on a categorized list differ in an obvious way from the items on a noncategorized list: They all belong to the same semantic category and presumably are closely linked in memory. So it is not clear that the extrapolation of the one situation to the other is warranted.

Hudson and Davis (1972) found that presentation of either one word or two from each of 15 three-word categories on a list had equally facilitative effects on the recall of the remaining words. The words in this case were all relatively highly associated with the name of the category to which they belonged.

Several experimenters have explored the consequences of varying over a wider range the number of instance cues that are given from the same category. In one experiment, Slamecka (1968, Experiment 4) gave subjects lists composed of 6 words from each of five categories, randomly ordered. At recall, experimental subjects were given either 5,15 , or 25 of the words as cues, an equal number of words being drawn from each category in every case. Performance of the cued subjects in recalling noncue words was slightly poorer than that of the controls. The failure of the indirect category cues to facilitate recall could have been due to a ceiling effect on category recall, inasmuch as the average number of categories recalled by control subjects was 4.88 . The inhibitory effect in this case was with respect to the recall of items within categories and was similar to the inhibitory effect of item cuing with uncategorized lists. Of course, the recall of categories per se could not be inhibited inasmuch as all categories were cued (by instances) if any were.

In the first of two experiments of a later study, Slamecka (1972) gave subjects lists composed of five words from each of 4,8 , or 12 categories. Items were presented once auditorily, blocked by category. At the time of recall, zero, one, or four list items per category were presented on the recall sheets as cues. The presentation of cues did not affect either the proportion of items recalled or the proportion of categories recalled when there were only 4 categories on the list; when there were 8 or 12 categories, the proportion of categories recalled was greater with one cue per category than with no cues, but not greater with four cues than with one. The proportion of items recalled per recalled category decreased as the number of categories increased, but was not affected by the presence or absence 
of cues. Cuing also decreased the accuracy of the recalls, inasmuch as the proportions of all responses that were intrusions were $.16, .20$, and .37 for the zero-, one-, and four-per-category conditions, respectively. In a second experiment, lists were composed of four words from each of 18 categories, each list was presented three times instead of once, and at recall time, zero, one, or three list words per category were presented as cues. The results of this experiment essentially replicated those of the first one in all major respects.

Slamecka suggested that recall from a categorized list may be reviewed as a generative process that is guided by the names of categories the subject knows to be represented on the list. A category name delimits an area of search, as it were; it facilitates the generation from long-term memory of items that might have occurred on the list and, in effect, transforms the recall task into something closer to a recognition task: "Thus, when the unit 'animals' is operative, $S$ generates conforming exemplars from his vocabulary and emits those which are recognized as list members" (Slamecka, 1972, p. 325). List items serve to cue categories, in Slamecka's view, and function very much like category names. Moreover, both list items and category names are facilitative only by way of providing access to categories that otherwise might not have been accessed; neither enhances access to items within categories. Slamecka interpreted the results of his series of studies and those of other investigators of cuing effects as strong evidence against an associative theory of learning. Such a theory cannot, he argued, incorporate the findings of these studies without abandoning a central feature of the term "association" and, in particular, the idea that an item has the power to elicit its associate.

In another study of the effects of varying the number of instance cues per category, Rundus (1973) had subjects listen to randomly ordered lists of 10 items from each of four categories. As recall cues, subjects were given a set of $\mathbf{8}$ items selected from the study list so as to vary the number of times individual study list categories were represented in this set from zero to four. Two effects were found: First, the probability of recalling at least one noncue item from any given category was higher for categories represented in the cue set than for those not represented; and second, considering only those categories from which at least one noncue item was recalled, the greater the number of items from a given category included in the cue set, the smaller the probability that any given noncue item would be recalled. Thus, presenting one instance from a category had an effect similar to that of presenting the category name; presenting multiple category instances had a within-category effect similar to that produced by part-list cuing with noncategorized lists.

Roediger (1973) gave subjects lists of 88 words from 16 categories, 4 categories with 4 words, 4 with 5,4 with 6 , and 4 with 7 . The words were presented once, auditorily, blocked by category, and the name of a category was given immediately before the items from that category. At recall time, subjects were given all 16 category names and, for 12 of the categories, varying numbers of category instances. Category instances had an inhibitory effect on the recall of other category instances, relative to recall with category-name cues alone. Moreover, the proportion of noncue items recalled per category generally decreased as the number of cues per category increased. The results as a whole were taken to be consistent with the hypothesis that cues aid recall when they provide access to more higher order units than could have been produced without them, and they impair it when they provide more information than is needed to provide this access.

\section{Cuing With Category Instances Not on the List}

In an experiment designed, in part, to investigate the effects of cuing with category instances not on the study list, Hudson and Davis (1972) used lists composed of four words from each of 10 categories. For some subjects the category instances were highly associated with their category names, and for others they were not. Subjects were given eight study-test trials, with the words presented in a different scrambled order on each trial. At each recall, subjects were given the name of each category, one of the items on the list from each category, an extralist instance from each category, or nothing. For subjects whose lists were composed of words highly associated with their category names, all the cues were facilitative, and whether or not the instance cues had been selected from the list made no difference. For the subjects whose list items were not highly associated with their category names, category names were facilitative, but neither type of instance cue was. These results are consistent with the idea that category cues are beneficial only to the degree that they do in fact increase the accessibility of the cued categories.

Lewis (1974) also got facilitative effects from using either category names or a single extralist item from each category as cues, whether or not items were blocked by category during presentation. Each subject had one study and one recall trial with eight 42 -word lists, each composed of 7 words from each of six categories. Some of the lists (for each subject) were blocked by category, and some were not. Recall was cued either by category names or by an extralist member of each category. For any given list, either all categories were cued or none was. Both types of cues increased the number of categories represented in recall but not the average number of items recalled per recalled category.

In another study of the effects of extralist cues, Watkins (1975) used lists composed of six words from each of six categories and four "buffer" items at each end to help control for primacy and recency effects. Each list was presented visually, one item at a time, only once, in scrambled order. At recall time, subjects were given the names of all the categories and, in addition, zero, two, or four category instances as cues. Some instance cues were taken from the study lists, and some were not. In- 
asmuch as subjects were always given all of the category names, this experiment does not speak to the question of the effectiveness of extralist cues to facilitate access to categories. However, it does address the question of whether extralist cues would have the same kind of withincategory inhibitory effects that presentation of multiple intralist instances of the same category has sometimes had. And the answer appears to be yes. The probability of recalling noncue items decreased as the number of category instances presented as cues increased, and by about the same amount when the instance cues were not from the original list as when they were.

Watkins's surmise as to why intralist and extralist category instances had equivalent inhibitory effects on item recall was that presentation of a recall cue may be tantamount to increasing the length of the list, whether or not the cue was on the original list. According to this hypothesis, presentation of a category instance would increase the number of instances nested under that category, and consequently would decrease the effectiveness of the category name as a means of access to any one of them.

In a second experiment designed to explore this idea, Watkins (1975) compared the effects of adding three or six category instances to a study list with those of presenting three or six extralist instance cues at the time of recall. (Category names were also given as cues.) The effect on the recall of "critical" words that were constant across conditions was inhibitory in all cases, but it was larger when the extra items were presented as cues than when they were added to the study list. Watkins interpreted the results of his experiments as evidence that the memory system has difficulty in using temporal information (the time of presentation of an item) as a basis for excluding items from consideration by the recall process. In particular, extralist cues seem not to be ignored even though one might think the fact that they were presented long after the study list would provide an adequate basis for permitting them to be.

In a follow-up study, Mueller and Watkins (1977) first showed that when words from a categorized study list were presented along with a category name at recall time, those words inhibited recall from the category only if they were names of instances of that category; names drawn from categories other than the one being tested had no effect. Mueller and Watkins then did three experiments to investigate the generality of the inhibitory effect of category members when they are presented as recall cues along with category names. In one experiment, all the words in the same category rhymed. In another, subjects sorted a set of words into a specified number of categories and then assigned a label to each category, in any way that made sense to them. In a third, each category was arbitrarily defined as all the words that had been paired with a given word in a series of paired-associate learning tasks in which each stimulus item had been paired with a different response item in each task (e.g., A-B, A-C, A-D). For all types of categories, the same result was obtained: When several members of the category were given as recall cues, along with the category name, recall of the remaining items in the category was inhibited.

\section{Summary of Findings With Part-Set Cuing With Categorized Lists}

- Presentation, as recall cues, of a single item from each of the categories represented in a categorized word list has facilitated recall in much the same way as has presentation of the category names. This result has been obtained sometimes (but not always) when the study lists have been scrambled with respect to category as well as when they have been blocked.

- Recall from categorized lists has typically been better when subjects have been given only the category names as cues than when they have been given the category names plus a subset of the items from each category.

- The facilitation that has resulted from the use of category instances as cues, like that that has resulted from the use of category names, has been attributable largely to an increase in the number of categories recalled and not to an increase in the number of words recalled per recalled category.

- The presentation of two or more instances from a category has not been more beneficial than the presentation of a single instance. Typically, when the number of instance cues per category has been varied, the greater the number of cues given from the same category, the smaller has been the probability of recalling any given remaining item in that category. This result has been obtained not only with semantically defined categories, but also with categories based on rhyming, subjects' own groupings, and arbitrary clusterings that have been learned for purposes of the experiment.

- The effects of presenting extralist category instances as cues have been similar, insofar as they have been investigated, to those of presenting instances selected from the study list.

- When words from a categorized list have been preented along with the name of a category at recall time, those words have not inhibited recall from the specified category if they were not names of instances of that category themselves.

\section{CUING AND RETRIEVAL FROM LONG-TERM MEMORY}

In the studies that have been considered so far, the subjects' task has always been to recall words from a list that had been studied shortly before the recall task. A few experiments have dealt with the question of the effectiveness of cues on the retrieval of words from long-term memory.

The first and best known study of this type was one conducted by J. Brown (1968). In the first of three experiments, Brown had subjects (United States college students) produce as many names of United States states as they could within a specified time. Before performing this task, half of the subjects studied the names of 25 of the states 
for $5 \mathrm{~min}$. These subjects did more poorly than the controls, who had not been given the list to study, in producing names of states not included on the study list. Brown's second experiment was similar to the first, except the items were the 40 counties of England and the subjects were English school children. The results showed the same trends as Experiment 1, but differences were not statistically significant. In the third experiment, subjects were first asked to name as many counties as possible during $6 \mathrm{~min}$, then the experimentals were given the names of 20 counties to study while the controls drew pictures, and finally all subjects again were asked to name as many counties as possible during $6 \mathrm{~min}$. During the second name-production period, control and experimental subjects produced, respectively, $11 \%$ more and $10 \%$ fewer of the names not on the study list than they produced during the first attempt.

Brown considered these results to be consistent with the hypothesis that strong associations block weak ones. Associations may be strengthened as the result either of studying items on a list or of retrieving them from memory. Memory retrieval is assumed to involve sampling with replacement, so items that have already been retrieved may interfere with the subsequent retrieval of other items.

In a follow-up to Brown's study, Karchmer and Winograd (1971) also had college students attempt to produce the names of all 50 United States states after studying a list of 25 states for $5 \mathrm{~min}$. For one experimental group, the cue list contained 25 states that had been most frequently produced by a group of the subjects' schoolmates in a previous study conducted to establish stateretrieval norms. For another group, the list contained the 25 states least frequently produced in the normative study. Control subjects in this experiment read a story for $5 \mathrm{~min}$.

Following the study of the cue list, or the reading of the story, subjects were asked to list as many of the $\mathbf{5 0}$ state names as possible in any order. Control subjects produced more noncue items than experimentals in general. Experimental subjects whose cue list was composed of the less accessible items did significantly worse than controls in producing the complementary sets; those whose cue list was composed of the more accessible items did not differ significantly from controls with respect to production of their complementary sets. (The difference beween the performance of experimentals and that of controls was slightly larger in the latter case than in the former, but variability was also greater, which accounts for the lack of statistical significance.) In a second experiment, similar in most respects to the first, the inhibition of the production of noncue items was statistically significant for both experimental groups.

Karchmer and Winograd (1971) considered the results of both of their experiments to be consistent with J. Brown's (1968) finding that "the accessibility of one part of a larger set may be decreased when the accessibility of the other part is increased by prior exposure"' (p. 225). They also concluded that the normative strength of a sub- set of items that a cue set comprises is of little importance in determining the extent to which they will inhibit the production of noncue items.

Nickerson, Smith, and Wallach (1984) conducted another study of the effects of cuing on retrieval from long-term memory. Some subjects produced names of birds; others produced names of countries. Just prior to performing the word-production task, subjects participated in a conventional list-learning experiment with a list of 20 bird names or 20 country names. For the experimental subjects, the list-learning and word-production tasks involved the same category (either bird names or country names in both cases); for the controls, the two tasks involved different categories (either bird names in the first case and country names in the second, or vice versa). The purpose of the list-learning task was to increase the accessibility of a subset of the target category for the wordproduction task for the experimental subjects. For the sake of consistency, we will refer to the subset of items used in the list-learning task as cues, which is the function they served for the word-production task. The 20 items that were used in the list-learning task, the cues, were selected so as to be either highly accessible or relatively less accessible, according to the Battig and Montague (1969) norms, and subjects were given either one or three studytest trials in the list-learning task. Contrary to expectations, independently of the a priori accessibility of the cues studied for the list-learning task and of the number of listlearning trials involved, experimental subjects produced at least as many noncue items on the production task as were produced by the control subjects, and in some cases they produced more.

The results of this experiment came as a surprise. The experimenters were looking for evidence of a relationship between degree of inhibition and cue accessibility, but had expected to obtain inhibition, or at least not facilitation, in all cases. Reflection on the differences between the specifics of this experimental situation and those of J. Brown (1968) and Karchmer and Winograd (1971) led to the post hoc conjecture that a critical variable might have been the sizes of target and cue sets. The target sets were considerably larger in the Nickerson et al. (1984) experiment than in the earlier ones, and the ratio of the sizes of cue sets to the sizes of target sets was relatively small. On the assumption that the search of memory for target items involves some quasi-random sampling with replacement, the process will return a higher proportion of cues from the beginning when the ratio of cue set size to target set size is relatively large. And given the recent strengthening of the cues as a result of their previous exposure, the probability is high that they will be sampled more than once. If the search process terminates when the cumulative number of false alarms (resampling) exceeds some criterion, it is likely to terminate relatively soon in this situation.

To explore this conjecture, the sizes of target sets and cue sets were varied independently. Target set size was varied by having subjects attempt to produce the names 
of countries in Europe and Asia in some cases and anywhere in the world in others. Cue set size was varied by having subjects perform a list-learning task either with bird names (controls) or with the names of 10, 20, or 30 countries in Europe and Asia (experimentals) before performing the name-production task.

Given 20 countries in Europe and Asia as the cue set, inhibition was obtained with subjects who attempted to produce only names of countries in Europe and Asia but not with those who attempted to produce names of countries from anywhere. When the target set was held constant (countries in Europe and Asia), the relative amount of inhibition increased with the size of the cue set, but not to a statistically significant degree. The results were considered suggestive but not conclusive evidence in favor of the conjecture regarding the importance of the relative sizes of cue and target sets in determining whether inhibition is likely to be obtained.

\section{Summary of Findings With Cued Retrieval From Long-Term Memory}

- When subjects have been asked to produce as many as possible of the items from some well-known set of modest size (states of the United States) providing a subset of the items as retrieval cues has not facilitated the retrieval of the noncue items, but has typically had a small inhibitory effect. The effect has been found independently of a priori accessibility of the items presented as cues.

- When subjects have been asked to produce as many as possible of the items from a relatively large and incompletely known category (names of birds or countries), study of a small subset of the items immediately before the word-production task has not inhibited the production of other items from the same category.

- Increasing the accessibility of the subset, either by selecting items highly associated with the category name or by increasing the subjects' exposure to the items, has not decreased subjects' ability to produce other items from the category.

- When the sizes of cue sets and target sets have been varied independently, inhibition has been more in evidence when the ratio of cue set size to target set size has been relatively large.

\section{THEORETICAL ACCOUNTS OF INHIBITION FROM PART-SET CUING}

Several experimental findings have been reviewed in the preceding sections. The most important of these findings, for purposes of this review, and the one that has come as a surprise to many investigators, is the fact that cues that one might think would facilitate recall or retrieval in certain specific ways often do not do so, and sometimes even have inhibitory effects. In particular, presenting some of the items from a noncategorized list fails to facilitate recall of the remainder of the items, and sometimes inhibits it; presenting the names of some of the categories represented on a categorized list fails to facilitate recall of the remaining categories, and sometimes inhibits it; presenting several of the items from a given category in a categorized list fails to facilitate recall of the remaining items from that category, and often inhibits it; and presenting some of the items from a familiar set that one has been asked to produce from long-term memory does not necessarily facilitate retrieval of the remaining items, and may inhibit it.

These results all appear to be the same phenomenon manifesting itself at different levels of organization and in different contexts. Certainly, it would be in the interest of parsimony to look for one explanation that would accommodate all of them. We turn now to a consideration of several explanations that have been proposed for such results.

\section{The Editing Task Hypothesis}

One possibility that has been suggested is that cuing imposes on subjects the extra task of checking each word that is recalled against the cues, or editing the cues out (Roediger \& Tulving, 1974). Roediger et al. (1977) rejected this possibility on the grounds that cuing reduces the asymptote of the cumulative recall curve even when subjects are given a relatively long time (e.g., $10 \mathrm{~min}$ for a list of 48 words) to recall. One should accept this reason for rejecting the explanation only if one is willing to assume that the extra task would, at worst, slow down recall, but not make it less productive given ample time. If one assumes that delaying the recall of an item could decrease the probability that it would ever be recalled (as would be the case, for example, if the strength of the item diminished during the delay), then the fact that cuing is detrimental even when the recall period is long does not rule out the extratask explanation of the inhibitory effect.

The finding of Watkins (1975) and of Roediger et al. (1977) that extralist cues can also have an inhibitory effect argues against the editing-task hypothesis. Inasmuch as the cues in this case were not contained on the study list, items recalled from the list would not have to be checked against them before being reported.

Basden, Basden, and Galloway (1977) have suggested that the editing of cues from recall may influence the order in which items are recalled, and the resulting recall order may be suboptimal relative to whatever organization the subject imposed on the items while studying them. Basden et al. considered this hypothesis to be consistent with all the results that had been obtained up to the time of their report. They themselves used both intralist and extralist cues with categorized lists and obtained no inhibition with the extralist cues. They considered the failure of extralist cues to produce inhibition to be evidence against Rundus's (1973) explanation of the part-list cuing effect (see below), but consonant with the editing hypothesis. Watkins's (1975) finding of an inhibitory effect with extralist cues was dismissed on the grounds that the mixed-list design of that experiment would have 
prompted subjects to use the same editing strategy for both extralist and intralist cues. Roediger et al.'s (1977) finding of an inhibitory effect with extralist cues is not so easily dismissed, however, inasmuch as any one of their subjects got either intralist cues or extralist cues, but not both.

Two other arguments can be made against the editing hypothesis. First, it does not seem to apply to the retrieval of words from long-term memory, at least if the subject is given ample time. Here, the editing process might slow down the rate at which target words are found, but it should not reduce the number that are found eventually; inasmuch as the words in this case are stored permanently, they would not be expected to fade from memory simply because their retrieval is delayed somewhat. Second, it also seems inapplicable to those experiments (e.g., Roediger et al., 1977, Experiment II) in which subjects who have received the cues have been asked to recall as many words as possible from the original list, including those words that were presented as cues. In this case, there is no need to edit out the cues, so there is no extra task. Of course, subjects must check recalled words against those that have already been recalled; however, this task is not unique to the experimental subjects, but is required also of controls.

\section{The Increased-List-Length Hypothesis}

Watkins (1975) suggested that the presentation of cues increases, in effect, the length of the list that one has to remember, and in so doing decreases the probability that any given item will be recalled. Watkins advanced this hypothesis to account for his finding that extralist cues drawn from categories represented on a categorized list inhibited recall, and by about the same amount as did intralist cues. Watkins concluded that presenting a list item as a recall cue is equivalent, in effect, to presenting a new category instance.

One limitation that this hypothesis shares with the editing-task hypothesis is that it also does not seem to apply to cases in which the task is to retrieve information from semantic memory rather than to recall it from episodic memory. The increased-list-length hypothesis also has some difficulties in accounting for the episodic recall results. Roediger et al. (1977) considered Watkins's (1975) increased-list-length hypothesis to be a compelling explanation of the inhibitory effect of extralist cues that they had found with uncategorized lists, except for two facts: The inhibitory effect of extralist cues was smaller than that of intralist cues, and subjects who received extralist cues produced critical items at a faster rate (approached asymptote more quickly) than did those who received intralist cues. They concluded that extralist cues that are not related to the items on the list probably affect recall differently from the way intralist cues do.

Another difficulty for the increased-list-length hypothesis is Mueller and Watkins's (1977) finding with categorized lists that cues that did not belong to the categories being tested did not inhibit recall. How to reconcile this result with Roediger et al.'s (1977) finding that cues un- related to words on an uncategorized list did inhibit recall is not clear. The two findings agree, however, in showing that unrelated extralist cues are not as inhibitory as intralist cues. Thus, if one wants to entertain the increasedlist-length hypothesis, one must recognize that not all items presented at recall time effectively extend the list, or at least not by the same amount.

The expectation that increasing list length would decrease the probability of recall of any given item presumably follows from the fact that, in free-recall tasks, the longer the study list, the smaller the percentage of items recalled (Murdock, 1960; Roberts, 1972). This finding is of questionable relevance to the part-set cuing experiment with intralist cues, however, because if we are to assume that the presentation of cues from the list effectively increases list length, we must recognize that it does so in a special way, namely, by making certain items (the cues) appear on the list twice.

Fortunately, there are some data on the question of how the appearance of twice-presented words on a study list affects the recall of words presented only once (Hastie, 1975; Tulving \& Hastie, 1972; Robbins, Bray, \& Irvin, 1974; Waugh, 1963). In the aggregate, the results support the conclusion that recall of once-presented items is not impaired by the occurrence of twice-presented items unless subjects are obliged to remember the fact that the latter occurred twice. Therefore, these results do not support the idea that the decrement observed in part-set cuing experiments is due to an effective lengthening of the study list by the presentation of cues. Subjects have never had to write the cue words twice or to report the number of times items have occurred on the list. In one paradigm they have had only to recall as many items as possible, without regard to whether the items had occurred as cues, and in another they have had to recall only the words that did not occur as cues; in neither case have they had any reason to believe they would have to report the cues twice.

\section{The Cue-Overload Hypothesis}

Mueller and Watkins (1977) provided a rationale for considering the presentation of a category instance as a recall cue to be equivalent, in effect, to presenting a new category instance. They assumed that the unit in episodic memory (which the word-list recall studies are assumed to tap) is not a word but an episode. Two occurrences of the same word, once as an item on the study list and once as a cue, represent two episodes; and the second occurrence effectively increases by one the number of episodes subsumed under a given category, much as does the presentation of a completely new item in that category. Increasing the number of episodes subsumed under a given category decreases the effectiveness of the category name to facilitate access to any one of them (and in particular to words that are represented by only a single episode). Mueller and Watkins referred to the process that is hypothesized to underlie inhibition as "cue overload"; it is assumed that all recall is mediated by cues and that 
what is happening in this case is that certain cuescategory names-are being "overloaded" by virtue of the presentation of either intralist or extralist category members at recall time.

The cue-overload hypothesis is similar to the increased-list-length hypothesis in most respects, but one thing the former does that the latter does not do is provide an explanation for why extralist cues that are not related to items on the list are not likely to have the same effects as those that are. Indeed, the cue-overload hypothesis would lead us to expect unrelated extralist cues to have no effect at all. This is consistent with the results of Mueller and Watkins's (1977) study, but not with that of Roediger et al. (1977).

\section{The Competition-at-Retrieval Hypothesis}

According to this hypothesis, the presentation of cues at recall time strengthens the memory representations of these items and increases their accessibility relative to that of the remaining items in the set; and the cues, being more accessible, are likely to be produced by the recall process, and consequently to block the recall of the less accessible noncue items. Some variant of this hypothesis has been espoused by several investigators, perhaps most explicitly by Rundus (1973).

The idea that the accessibility of cues is increased by virtue of their presentation at recall time and that this increase means a decrease in the accessibility of noncue items is independent of the structure of the study lists; however, Rundus's (1973) hypothesis was proposed in the context of an experiment with categorized lists, and his account of how the changes in accessibility occur applies primarily to such lists. According to the hypothesis, items are organized hierarchically in memory, and items emanating from a common node in the hierarchy can be accessed via that node; thus, presentation of a category name during recall can cue the recall of instances of that category. Facilitation should be obtained, of course, only if the cued category is one that the subject would not have recalled spontaneously. A category instance could also be an effective recall cue, albeit an indirect one: The instance would cue the category name, which in turn would cue other instances.

The idea that memory for categorized lists is organized hierarchically, with the associations being primarily vertical ones between items at different levels of the hierarchy (e.g., category names and category instances) as opposed to horizontal ones between items at the same level, is a fairly prevalent one (Bower, Clark, Lesgold, \& Winzenz, 1969; Estes, 1972; Johnson, 1970; Mandler, 1967; Mathews \& Tulving, 1973; Shiffrin, 1970; Slamecka, 1968, 1972; Tulving, 1964, 1968). Any node is viewed as a "control" element for the subordinate nodes that emanate from it (Estes, 1972). The strength of the relationship between a control element and its subordinate nodes is what determines whether a particular item will be produced when its control element is accessed.
In Rundus's (1973) terms, the nodes at a given level in this hierarchy are referred to as retrieval cues with respect to their subordinate nodes. Memory search for items in a categorized word list is assumed to occur at two levels, that of the cues, or category names, and that of the immediately subordinate words, or category instances. One searches first for a cue, and then, with cue in hand, one searches the set to which that cue provides access. Two key assumptions of the model are: (1) that when an item is recalled it is not deleted from the representation and thus remains available for subsequent recall attempts, and (2) that either the act of processing an item that is presented as a cue or recalling an item from memory strengthens that item and its relationship to its control element. Thus, at both levels, search involves sampling with replacement; so finding an item does not preclude finding it again. Indeed, the probability that an item will be found is assumed to depend on its strength relative to the strength of all the other items accessed via the same cue (ratio rule), and finding an item is assumed to increase its strength and consequently also the probability that it will be found again. According to this model, the presentation of list items as recall cues inhibits the recall of noncue items at the same level because the processing of the cues increases the strength of their representations in memory and hence increases the probability of their subsequent recall; and, by the ratio rule, increasing the probability of accessing a cue necessarily decreases the probability of accessing any other item at the same level on a given attempt.

J. Brown's (1968) conjecture as to why categoryinstance cues might have an inhibitory effect on the retrieval of category items from long-term memory was similar in many respects to Rundus's (1973) account of the part-set cuing effect. Brown suggested that the mechanism by which highly accessible cues may interfere with the retrieval of noncues is one of intrusion or retrieval interference: Given that items are not deleted from the search space when they are produced, they may recur frequently by virtue of their relatively high accessibility, and in doing so lower the probability of retrieval of the less accessible items.

A question that occurs with respect to the competitionat-retrieval hypothesis is why the probability of recalling some items should decrease just because the probability of recalling others has increased. Given that one can recall (or at least report) only one item at a time, it is clear that if the probability of recalling a particular item at a given instant is increased, the mean probability of recalling any other particular item at that instant must decrease. However, it does not follow that an increase in the probability that a particular item will be recalled sometime during the recall period must be offset by a decrease in the mean probability that other items will eventually be recalled. One consequence of an effective learning process is to increase the probability that all the studied information will be recalled. Why should increasing the acces- 
sibility of some items on a list-recall task necessarily produce an offsetting decrease in the (eventual) accessibility of other items?

According to Rundus's (1973) model, increasing the probability of recalling certain items decreases the probability of ever recalling the other items because it makes it less likely that the latter items will be recalled before a stopping rule that terminates search is reached. Search at a given level is assumed to be terminated when the process yields a predetermined number of successive items that have already been recalled. Thus, when search within a category produces the requisite number of items that have already been recalled, it is switched to another category; all search is terminated when a similar stopping criterion is reached at a higher level.

Of the several possible explanations that Roediger et al. (1977) considered, they found the competition-at-retrieval hypothesis to be most consistent with their own data. An aspect of the results that they considered particularly supportive of this hypothesis was the fact that subjects who had received list cues and who were asked to recall as many as possible of the original words (including cue items) tended to recall cue items to the neglect of noncue items during the early minutes of the recall period.

One problem for the competition-at-retrieval hypothesis is Basden et al.'s (1977) finding that in a recall attempt without the presence of cues, following the primary recall task in which some subjects had cues and some did not, subjects who had had the cues on the earlier task did as well as those who had never seen them. The cued subjects had done more poorly than the uncued subjects on the cued recall task, and the equivalent performance of the two groups on the subsequent uncued recall task reflected recovery from the inhibitory effects. Basden et al. considered this result to be a problem for Rundus's (1973) model because, in spite of the fact that cue words were strongly represented in memory at the time of the uncued task (as evidenced by the fact that subjects who had received cues on the earlier task recalled cue words better than they did noncue words on the subsequent uncued task), the cue words did not inhibit the recall of noncue items, at least to a statistically significant degree, when they were not present during the final recall task.

An aspect of their findings that Roediger et al. (1977) felt that the competition-at-retrieval hypothesis did not explain was the finding that extralist cues also can have an inhibitory effect. Basden et al. (1977) argued, however, that although Rundus (1973) did not discuss extralist cues, his model, or a logical extension of it, does provide the basis for a prediction about the effect of such cues on the recall of categorized lists. (Roediger et al. used noncategorized lists.) The argument is similar to that of Mueller and Watkins (1977) in their development of the cue-overload hypothesis. If one assumes that extralist instances of categories represented on a list increase the number of items associated with their respective category labels, then, by the ratio rule, the presentation of such items should decrease the probability of recall of other items within the same categories. In an experiment in which both intralist and extralist cues were used, Basden et al. found that the former inhibited recall of uncued items, but that the latter did not. They considered this result to be at odds with Rundus's model but consistent with the editing or disrupting hypothesis. We should note that the result is also at odds with that of Watkins (1975), who got inhibition when extralist category instances were used as cues. Given that extralist cues have been shown to be inhibitive in some instances, the fact that they have not been in others is probably not strong evidence against a hypothesis that predicts their occurrence.

Roediger (1978) interpreted the results of his experiments with categorized lists and others of the same type to be consistent with a process such as that hypothesized by Rundus (1973). And he saw them as favoring the idea that vertical associations (Segal \& Mandler, 1967; Wickelgren, 1976) facilitate the recall of categorized lists, whereas horizontal associations, either among categories or category instances, do not. Providing a category name facilitates access to items within that category but inhibits access to other category names. The inhibition is a consequence of the strengthening of the vertical associations between the category name and the instances that are recalled. The act of recalling is assumed to have an effect analogous to additional study time. Because the process underlying recall is assumed to involve sampling with replacement, the strengthening of a given association increases the probability of subsequent recall of the same item, which indirectly decreases the probability of the recall of other items.

Roediger (1973) and Roediger and Schmidt (1980) have argued that Rundus's (1973) model can account for the inhibition that occurs when subjects are given a subset of category names or list items as cues, but that it does not account for the finding (e.g., Roediger, 1973; Roediger \& Schmidt, 1980; Smith, 1971, 1973; Smith et al., 1970) that when subjects are given all the category names as cues, recall of items from the categories specified first impairs recall of items from categories specified later. According to Rundus's model, interference between categories would be expected to occur when categories are not cued, because the categories that are recalled earlier would tend to block (by virtue of being recalled) the recall of those that were not produced first; however, that does not explain why one gets betweencategory interference when all the categories are cued so that category recall (as opposed to item recall) is perfect.

Basden et al. (1977) argued that the ratio rule is a major weakness of Rundus's (1973) model. This rule makes the probability of retrieval of a noncue item strictly a function of its strength relative to the sum of the strengths of the other items in the category and independent of absolute strengths. (Strength here means strength of association of an item with its category label.) Thus, the probability of recalling a weakly associated item among $n$ 
equally weakly associated items should be the same as the probability of recalling a strongly associated item among $\mathrm{n}$ equally strongly associated items. Consider, in particular, three types of lists: (1) all items are strongly associated with their category labels; (2) all items are weekly associated with their category labels; and (3) half of the items are strong associates of their labels, and half are weak. Rundus's ratio rule predicts that the strongly associated items in a Type 3 list would be recalled more effectively than strongly associated items in a Type 1 list. Similarly, weakly associated items on a Type 3 list should be recalled less effectively than weakly associated items on a Type 2 list. Basden et al. did essentially this experiment but did not get the predicted results. Strongly associated items were not recalled better when mixed with weakly associated items than when mixed with strongly associated items, and weakly associated items were not recalled more poorly when mixed with strongly associated items than when mixed with other weakly associated items.

Basden et al. also considered what to expect when either strongly or weakly associated items are explicitly given as cues (in the situation described above, they were not), and they noted that predictions are less clear in this case. However, they inferred from Rundus's (1973) model that recall of noncue items would be better if cue words were weakly associated items than if they were strongly associated items, although it would be inhibited in both cases. In an experiment to check this prediction, they found inhibition in both cases, but the prediction with respect to the differential effect of weakly and strongly associated cues did not prove correct. In fact, although the difference was not quite statistically significant, strongly associated cues produced greater recall than did weakly associated cues. Basden et al. considered these results to be damaging not only to Rundus's model but also to "any explanation that postulates that the inhibitory cuing effect results from the blocking of weak items by strong"' ( $p$ 104). They concluded in favor of the hypothesis that inhibition is due to the need to edit cue words, because such editing disrupts the recall process.

\section{The Organizational-Interference or Strategy-Disruption Hypothesis}

Items stored in memory-whether short- or longterm-must be organized in some way. Presumably, one takes advantage of that organization when accessing memory. One effect that the presentation of cues might have is to interfere with this organization or to impair the subject's ability to use a retrieval strategy that uses it to advantage (A. S. Brown \& Hall, 1979; J. Brown, 1968; Slamecka, 1968, 1969). As we have noted, Basden et al. (1977) suggested the possibility that the editing of cues from recall may influence recall order; there is also the possibility that the mere processing of the cues, before any attempt to retrieve any items from memory, would affect the order in which items are subsequently recalled.
A. S. Brown and Hall (1979) obtained results that they interpreted to be consistent with this hypothesis and inconsistent with several others that we have considered. They had subjects free-associate four responses to each of 20 stimulus words. Two days later, the same subjects unexpectedly were asked to reproduce the same responses as cues. Although the description of the procedure is not clear on this point, they presumably were given the original 20 stimulus words as well. For all of the subjects, some of the response sets were cued and some were not. However, the number of cues provided (one, two, or three) was a between-subjects variable. Cuing proved to be inhibitory, and the magnitude of the inhibition was relatively independent of the number of cues and of their output position in the initial free-association task.

Brown and Hall interpreted these results as being inconsistent with several of the theoretical accounts of cuing inhibition, namely, competition at retrieval (in their terms, strength dominance) (Rundus, 1973), cue overload (Mueller \& Watkins, 1977), and editing interference (Basden et al., 1977). The strategy-disruption hypothesis, they argued, is the only one that can accommodate the lack of dependence of magnitude of inhibition on number of within-category cues.

A problem with this explanation is that its credibility, according to Brown and Hall, rests with this lack of dependence. Although Brown and Hall found no relationship between magnitude of inhibition and number of cues within a category, several other investigators have found them to be positively related (Roediger, 1973; Rundus, 1973). One might question whether independence between these variables really is implied by the hypothesis; if it is not, however, it is not clear that the hypothesis is falsifiable.

\section{The Interference-With-Maintenance Hypothesis}

An important aspect of Rundus's (1973) model is that it does not attribute the decreased accessibility of noncues to a decrease in their "strength" or, indeed, to any change in their memory representation at all. According to that model, decreased accessibility is a consequence of changes in the strengths of other items. What is critical to Rundus's model is the assumption that the presentation of cues changes the relative strengths of cues and noncues; the model would produce the same predictions if this change were assumed to be due to a decrease in the strength of the noncue items as it does when the change is assumed to be due to an increase in the strength of the cue items.

One rationale for considering the possibility that the processing of cues might weaken the representation of noncues is the assumption that items in secondary memory must be actively maintained and that anything that interferes with that maintenance weakens the representations of those items. Given this assumption, one way to interfere with the maintenance of some items would be to engage the maintenance resources with other items. If, when 
a cue is processed during the recall task, some fraction of the resources that are otherwise used for maintenance is diverted, then the more the processing of cues drained resources, the greater would be the decrease in the accessibility of the other items.

The finding that the percentage of words recalled from a given category falls off with the position of the category in a recall sequence is consistent with the idea that the recall of some items interferes with the maintenance of others, and consequently permits the diminution of their strength or accessibility. One might try to attribute this result to the effects of proactive inhibition: The learning of the items in a category that was presented late on the study list could have been subject to proactive inhibition from the earlier items on the list. In fact, however, the result has been obtained even when the order in which the categories were specified at recall was independent of the order in which they occurred on the study list (Smith, 1973).

Attributing the decline in recall with category position to retroactive inhibition is also a possibility. Except when recall order matches order on the study list, the categories recalled last are likely to have had more items intervening between their original occurrence on the study list and their recall (assuming one considers both an original presentation and a recall as an "item") than are items that are recalled first, and therefore the former are more subject to retroactive interference effects. In assessing the possibility of such effects, one must bear in mind also that among the "items" that intervene between the initial presentation of an item and its recall are the covert recalls that are not reported. With respect to the possibility that cue items are recalled whether or not subjects are required to report them, Roediger et al. (1977) noted that in their studies subjects who recalled all items and those who recalled only the noncue items produced noncue items at about the same rate even during the first few minutes of recall. They saw this as suggestive evidence that subjects covertly recalled cue items even when they did not have to produce them.

An experiment that is relevant to the question of the possible role of retroactive interference effects in these studies is one conducted by Tulving and Psotka (1971). They had subjects study lists composed of four words from each of six categories. Each list, blocked by category, was presented visually three times, one word at a time. Each subject studied from one to six different lists. Following study and recall tests for the lists individually, subjects were given two total-recall tests (separated by a 10-min filler activity) on which they attempted to recall all the words from all the lists they had studied. The number of words and number of categories recalled per list decreased as the number of lists that a subject had studied increased, but the number of words recalled per recalled category remained relatively constant. The changes in number of words and categories recalled on the total-recall tests were such as could be attributed to retroactive inhibition; for example, the number of words or categories recalled from a given list fell off sharply as the number of lists that intervened between that list and the total recall tests increased. Following the second total-recall test, the names of all the categories a subject had studied (which varied from 6 to 36) were provided, and a final total-recall test was given with these names in hand. Provision of the category names increased the number of words and categories recalled, but not the number of words recalled per recalled category. The increase in words and categories recalled was sufficient to offset the retroactive inhibition effects. Thus, retroactive inhibition had apparently had its effect by decreasing accessibility, not to items, but to categories, and presenting category names made accessible the categories that had become inaccessible as a result of retroactive inhibition from the learning of interpolated lists.

This result suggests that retroactive inhibition does not account for why the number of items recalled per category has sometimes fallen off with position of the category in the recall sequence. Indeed, the result is difficult to reconcile with that finding, because it suggests that the inhibitory effects are at the level of category recall and not item recall. But in experiments in which all the categories have been cued, there is no question of retroactive interference's making the categories per se inaccessible. A reconcilliation of the results of experiments showing a decrease in items per (cued) category with position of category in the recall sequence and those of experiments showing relative constancy of items recalled per recalled category remains to be made.

A result that seems to support the idea that maintenance of the representation of items in secondary memory requires some active process and that the act of recall can interfere with that process comes from some experiments by Epstein $(1969,1970)$, who gave people two relatively short lists (eight items each in the 1970 study) to remember and then asked some of the subjects to recall one of these lists and others to recall both of them. Performance was better on a given list when that list was the only one to be recalled than when it was the first of two to be recalled. (See also Dong, 1972.) The effect was more pronounced when the first or only list to be recalled was the second of the two lists presented. The results suggest that the need to maintain both lists in memory interferes with recall or, conversely, that the process of recalling some items interferes with the maintenance of others.

A limitation of the interference-with-maintenance hypothesis is its inapplicability to the studies of retrieval from long-term memory. In general, the plausibility of the hypothesis decreases as the retention interval and the amount of information retained increase. It is easiest to accept when the number of items to be recalled is relatively small and the interval brief, which is to say, when the situation is close to one in which active rehearsal is a possibility, for at least a significant subset of the list. It seems to be questionably applicable to many of the recall 
studies and totally inapplicable to the studies requiring retrieval from long-term memory. In the case of $\mathrm{J}$. Brown's (1968) experiment, for example, one could hardly argue that the strength of the memory representations of names of the states and counties decreased as a consequence of lack of attention while the subjects' resources were devoted to the processing of the state or county names presented as cues.

\section{The Associative Sampling-Bias Hypothesis}

Several investigators, beginning with Slamecka (1968, 1969,1972 ), have taken the failure of part-set cuing to facilitate recall of uncued items as evidence that items are not directly linked associatively in memory, although vertical or hierarchical associations are not ruled out (Roediger, 1974; Rundus, 1973; Watkins, 1975). Raaijmakers and Shiffrin (1981) challenged this interpretation on the grounds that it is inconsistent with such documented results as the effects of input order on output order (Anderson, 1972; Kintsch, 1970; Shiffrin, 1970), the effects of associativity of continuously presented items on recall (Glanzer \& Schwartz, 1971), and the fact that single-trial paired-associate learning occurs at all.

Among other findings that would seem to be inconsistent with the assumption that items are not associatively linked in memory is that of Deese $(1959,1961)$, that recall is better when stimulus words are highly associated with each other than when they are not, and that of Jenkins and his colleagues, that when a stimulus list contains pairs of closely associated words, the associates tend to be recalled together even when they were not together on the study list (Jenkins, Mink, \& Russell, 1958; Jenkins \& Russell, 1952). The well-known finding of category clustering in recall (Bousfield, 1953; Bousfield \& Sedgewick, 1944) is not relevant to this issue, inasmuch as investigators who have concluded that interitem associations are not important in memory for word lists typically have not ruled out the importance of vertical, or word-category, associations; what is relevant, however, is the fact that interitem association and category membership have both been manipulated in some studies and have both been shown to have effects (Bousfield \& Puff, 1964; Cofer, 1965; Marshall, 1967).

A possible way around these difficulties is to argue that interitem associations could play a role in the recall process without being implicated in the representations of the list items in memory. Such associations could come into play at the time of recall, by, for example, helping to direct the memory search. One variant of this view is represented by Slamecka's (1968) suggestion that the types of clustering that are sometimes seen in recall could be the results of a recall plan that applied to independently stored items, based on an awareness, at the time of recall, of the structure of the studied list. This view, however, seems to require two assumptions: (1) that interword associations are part of the long-term memory representations that exist prior to and independently of exposure to a study list during an experiment, and (2) that the memory representation of a study list that is constructed as a result of performance of the experimental task is independent of those long-term representations. The first assumption is necessary to explain associative effects that have been obtained, such as the effectiveness of extralist items as recall cues (Bahrick, 1970; Nelson \& McEvoy, 1979a, 1979b; Nelson et al., 1982; Tulving \& Pearlstone, 1966). The second one is necessary if one accepts the first one and still wishes to maintain that list items are stored independently of each other. (The second assumption, however, causes problems of another sort. For example, if the memory representations that are constructed for purposes of the experiment are independent of long-term memory representations of the words, how is it that the words are recognized as words during the study phase of the experiment?)

Raaijmakers and Shiffrin (1981) avoided such problems altogether in their account of the part-list cuing effect. Their model, which is similar in many respects to that of.Rundus (1973), assumes that the search of memory for list items is based on cues whether or not such cues are provided by the experimenter. Cues of two types are postulated: context cues and context-plus-word cues. The model assumes that the subject searches memory on the basis of particular cue until a new item is found or a stopping criterion (a preset number of failures to find a new item) is reached, at which time the cue in hand is discarded in fayor of a new cue, and the stopping-criterion index is reset to zero. Word cues may be provided by the experimenter, or they may be generated by the subject in the process of recalling words from the study list.

When word cues are not provided by the experimenter, each word the subject recalls is used as a cue in a search for additional words. Whenever the search produces a new word, the cue in hand is discarded and the new word becomes the cue for subsequent search. If the stopping criterion for searching with a specific cue is reached before a new word is produced, the cue is discarded in favor of a context-only cue. The primary search phase of the process is terminated when a second, more general, stopping criterion is reached (which is a preset total number of failures to find a new word). In the final phase of the process, which is known as the rechecking phase, each of the recalled words is again used as a cue for an additional attempt to find new items. The rechecking phase is included in the model to accommodate the possibility that the utility of a given cue may not be fully "used up" by the finding of a single word.

The model assumes that when cues are provided by the experimenter, the subject searches on each of them before using as cues any of the noncue words recalled. After having searched on the basis of each of the provided cues, the subject begins to use recalled words as cues, and from then on the process is equivalent to that followed when cue words are not provided.

An important aspect of this model is the assumption that interitem associations are used extensively whether or not cues are provided by the experimenter. Indeed, the as- 
sumption of associative clustering provides a rationale for the expectation that cuing will have a detrimental effect. Suppose, to use the simplified model that Raaijmakers and Shiffrin (1981) employed to illustrate how associations can have their effect, that words from a study list are organized in memory as several clusters, with a few words being in each cluster, and that the words in a cluster are sufficiently strongly associated with each other that if one of the words of the cluster is presented as a cue, or is recalled, all the remaining words in that cluster will be recalled as a consequence. Suppose further that, during a fixed time, experimental subjects, for whom cue words are provided, and controls, for whom they are not, sample the same number of different clusters. The presentation of the cue words to the experimental subjects will ensure that these subjects will sample all the clusters containing such words. Inasmuch as the controls are not subject to the same influence to sample clusters containing cues, they should sample fewer than all of these and consequently they should sample more of the clusters containing no cues than do the experimentals. On the assumption that all clusters contain about the same number of items, clusters that contain no cues will contain more target items (noncues) than those that contain one or more cues. It follows from these considerations that control subjects will find more target items than will the experimental subjects.

A model that explains the part-set cuing effect without denying the existence of interitem associations, and that, indeed, identifies those associations as the basis for the effect, is clearly of great interest. To investigators who believe in horizontal associations, the effect has been an enigma. Here is an account of the effect that recognizes the role of those associations and makes the enigma go away. Does it have a fatal flaw?

It is clear that the model predicts many of the results that have been obtained by investigators of part-set cuing, and several others as well. How satisfying one finds the model to be is likely to depend on how plausible one considers its underlying assumptions to be. One that not all investigators will find easy to accept is the assumption that the search of memory by subjects who are given cues is done on all of the cue words before it is done on any of the recalled words. A second one is the assumption-in the simplified illustration of the effects of associative clustering-that experimental and controls sample the same number of clusters. If one makes the assumption, one can account for the inhibitory effect of cuing, but why should one make the assumption-and would one make it if it were not necessary to do so to account for the effect? In making the assumption, we seem to be trading one enigma for another. Why should we not expect experimental subjects to sample a greater number of clusters than controls? In particular, why should we not expect them to sample all those they would have sampled had they not been given cues, plus all the cued clusters not included in their uncued sample?
Finally, even if one accepts the assumption that experimental and control subjects sample the same number of associative clusters, the explanation is applicable only to those experiments in which the words on the lists do, in fact, fall into several associative clusters. Although it is perhaps not possible ever to be certain that no such clustering occurs, at least we know that some of the lists that have been used were intended to contain words that were not related in any systematic way.

\section{CONCLUDING COMMENTS}

Research on part-set cuing began with the finding that the presentation of a subset of the items to be recalled on a list-learning task does not necessarily facilitate the recall of the remaining items and may inhibit it. This finding was surprising to many investigators and seemed to be at odds with the widely held idea that words are associatively linked in memory in such a way that activation of a given word should increase the accessibility of its associates. The idea that items are associatively linked in memory gets experimental support from a variety of sources, one of which is the fact that retrieval cues do sometimes facilitate recall.

The original finding of inhibition from part-set cuing motivated numerous experimenters to study further the effect. One of the consequences of the experimentation that has been done is a better understanding of the conditions under which cuing is likely to be facilitative and those under which it is likely to be inhibitory. With respect to this issue, the evidence gathered to date suggests the following conclusions.

When the items to be recalled are organized, or organizable, in categories or other comparable units, and the number of such units is large enough that they cannot all be recalled spontaneously, presentation of category names or other cues (such as intralist or extralist category instances) that identify the organizational units, will be generally facilitative. When only a subset of the units is cued, the effect of the cuing on the cued units is likely to be facilitative, but the effect on the uncued units is likely to be inhibitory, or at least not facilitative. The effectiveness of the cuing is likely to depend both on the distinctiveness of the categories, or other organizational units, and on how representative the items are of the categories or other units to which they belong. When items to be produced from long-term memory are not organized, and not organizable in a straightforward way, or they all belong to the same category (e.g., states), presentation of a random subset of the items as cues is likely not to facilitate the retrieval of the remaining items and may inhibit it slightly. This generalization may apply only when the target set is of moderate size and the cue set a sizable fraction of it.

With respect to retrieval from long-term memory, the randomness of the cue set is perhaps a more important consideration than has been generally noted. The point 
may be illustrated by the following conjectural experiment. Suppose subjects were asked to name the states of the United States and were given 25 state names as cues, selected, with the subjects' knowledge, in each of the following ways: (1) the first (or last) 25 states from an alphabetical listing, (2) alternating states from an alphabetical listing, (3) the 25 easternmost (or westernmost) states, (4) 25 states chosen in such a way that (with the exceptions of Alaska and Hawaii) for every state that is not used as a cue there is within the cue set at least one state that borders on it, and (5) 25 randomly chosen states. The experiment should perhaps be done. A priori, it seems unlikely that these cue sets would produce the same results.

Almost all of the experiments on part-set cuing have used target sets of only modest size (typically not more than a few tens of items), and cue sets have typically represented a sizable fraction of the target size. An exception in which the target sets contained a relatively large number of items (165 to about 350 ) failed to show inhibition as a result of cuing with small fractions (20 items) of these sets (Nickerson et al., 1984). This variable deserves further exploration. In the meantime, the explanations of the inhibition effect that have been offered should probably be considered limited to the more typical case of small sets.

What of the various explanations of the part-set cuing effect that have been offered? Cuing does, sometimes, impose on subjects the task of checking recalled words against cues, and we cannot rule out the possibility that when this checking is required, it interferes to some degree with the primary task. The fact is, however, that inhibition is obtained in situations in which such checking is not necessary as well as in those in which it is. It may well be that subjects sometimes process cues in such a way that presenting them effectively extends the study list. But, in view of the evidence that presenting some words twice in a conventional list-recall task does not necessarily impair the recall of the once-presented words, this too does not seem to be an adequate explanation of the inhibitory effect; and, in any case, it does not apply to situations in which items are retrieved from long-term memory. It may be that when category instances are presented as cues, they sometimes overload higher order cues (category names) and thereby make them less effective access routes to other specific category members, but this explanation suggests that extralist cues that are not members of the categories represented on a categorized list should not have any effect, and sometimes they do.

The hypothesis that experimenter-provided cues compete with other items at recall time seems quite consistent with most of the experimental results. Moreover, the hypothesis can be derived from an elegantly simple set of assumptions about the nature of the memory search process. This explanation requires the assumption, however, that increasing the probability of retrieval of one item from memory necessarily decreases the mean probability of retrieving any other item, not just momentar- ily, but indefinitely. And we know from countless studies of learning that (fortunately) an increase in the accessibility of one part of a list need not be offset by a decrease in that of another, and that, indeed, it is possible to increase the accessibility of all the items on a list more or less simultaneously. Moreover, there are some results that the competition-at-retrieval hypothesis, at least as incorporated in the model proposed by Rundus (1973), does not explain: the fact that recall from cued categories falls off with the position of the category in the recall sequence; and the fact that the accessibility of an item, given a recall cue, is not determined solely by the strength of association of that item to the cue relative to the strengths of the other items (as the ratio rule would predict).

The idea that the presentation of cues interferes with the organization of items in memory or impairs the subjects' ability to make effective use of that organization is a highly plausible one, but the only unique prediction that has been associated with it (independence between magnitude of inhibition and number of within-category cues) has been shown not always to hold. Moreover, the idea does not lead one to expect unrelated extralist cues to be inhibitory, and, in at least one case (Roediger et al., 1977), they have been. The assumption that the memory representations of items that have just been studied have to be maintained actively in order to remain accessible can account for many of the effects that have been reported, but it is not applicable to the case in which the task requires retrieval from long-term memory.

The sampling-bias model proposed by Raaijmakers and Shiffrin (1981) is, in several respects, the most adequate account of the inhibitory effects of part-set cuing that has been produced. It is the most quantitative of the models proposed and makes the most precise predictions; the applicability of the model extends far beyond part-set cuing; and, rather than deny associations, it identifies them as the cause of the inhibitory effect. However, this model makes some assumptions the only justification for which seems to be the fact that they are needed to explain the effect.

In summary, all of the explanations that have been proposed can account for some subset of the data; and, quite possibly, none of them is entirely wrong. However, none of them is completely able to account for all the data and is also compelling with respect to its underlying assumptions.

This paper has focused on cue inhibition in recall and retrieval tasks. It is worth noting that the possibility of inhibitory effects of other types has also been investigated. Several investigators have reported inhibitory effects from the use of list items and related "primes" as cues in recognition-memory tasks (A. S. Brown, 1981; Neely, Schmidt, \& Roediger, 1983; Roediger, Neely, \& Blaxton, 1983; Slamecka, 1975; Todres \& Watkins, 1981), but the determining conditions for such effects are not yet well understood. One hopes eventually for an account that will accommodate these situations as well as 
the recall and retrieval tasks reviewed in this report. For the present, inhibition of the sort first reported by Slamecka (1968) and subsequently observed in a variety of contexts remains something of an enigma in memory research.

\section{REFERENCES}

ALLEN, M. M. (1969). Cueing and retrieval in free recall. Journal of Experimental Psychology, 81, 29-35.

ANDERSON, J. R. (1972). FRAN: A simulation model of free recall. In $\mathrm{G}$. H. Bower (Ed.) The psychology of learning and motivation: Advances in research and theory (Vol. 5). New York: Academic Press.

Bahrick, H. P. (1970). Two-phase model for prompted recall. Psychological Review, 77, 215-222.

BASDEN, D. R. (1973). Cued and uncued free recall of unrelated words following interpolated learning. Journal of Experimental Psychology, 98, 429-431.

BASDEN, D. R., BaSDEN, B. H., \& Galloway, B. C. (1977). Inhibition with part-list cuing: Some tests of the item strength hypothesis. Journal of Experimental Psychology: Human Learning and Memory, 3, $100-108$

Battig, W. F., \& Montague, W. E. (1969). Category norms for verbal items in 56 categories: A replication and extension for the Connecticut category norms. Journal of Experimental Psychology Monographs, 80(3, Pt. 2.)

Bellezza, F. S., HarTwell, T. C. (1981). Cuing subjective units. Journal of Psychology, 107, 209-218.

BLAKE, M., \& OKADA, R. (1973). Intralist cuing following retroactive inhibition of well-learned items. Journal of Experimental Psychology, 101, 386-388.

Bousfield, W. A. (1953). The occurrence of clustering in the recall of randomly arranged associates. Journal of General Psychology, 49, 229-240.

Bousfield, W. A., \& PUFF, C. R. (1964). Clustering as a function of response dominance. Journal of Experimental Psychology, 67, 76-79.

Bousfield, W. A., \& SEDGEwick, C. H. W. (1944). An analysis of sequences of restricted associative responses. Journal of General Psychology, 30, 149-165.

Bower, G. H., Clark, M. C., Lesgold, A. M., \& Winzenz, D. (1969). Hierarchical retrieval schemes in recall of categorized word lists. Journal of Verbal Learning and Verbal Behavior, 8, 323-343.

Brown, A. S. (1981). Inhibition in cued retrieval. Journal of Experimental Psychology: Human Learning and Memory, 7, 204-215.

Brown, A. S., \& Hall, L. A. (1979). Part-list cuing inhibition in semantic memory structures. American Journal of Psychology, 92 , 351-362.

BRoWN, J. (1968). Reciprocal facilitation and impairment in free recall. Psychonomic Science, 10, 41-42.

CoFER, C. N. (1965). On some factors in the organizational characteristics of free recall. American Psychologist, 20, 261-272.

CoHEN, B. H. (1963). Recall of categorized word lists. Journal of Experimental Psychology, 66, 227-234.

DEESE, J. (1959). Influence of inter-item associative strength upon immediate free recall. Psychological Reports, 5, 305-312.

DEESE, J. (1961). From the isolated verbal unit to connected discource. In C. N. Cofer (Ed.) Verbal learning and verbal behavior. New York: McGraw-Hill.

DoNG, T. (1972). Cued partial recall of categorized words. Journal of Experimental Psychology, 93, 123-129.

DoNG, T., \& KINTSCH, W. (1968). Subjective retrieval cues in freerecall. Journal of Verbal Learning and Verbal Behavior, 7, 813-816.

EPsteIN, W. (1969). Post-stimulus output specification and differential retrieval from short-term memory. Journal of Experimental Psychology, 82, 168-174.

EPSTEIN, W. (1970). Facilitation of retrieval resulting from post-input exclusion of part of the input. Journal of Experimental Psychology, 86, $190-195$

ESTES, W. K. (1972). An associative basis for coding and organization in memory. In A. W. Melton \& E. Martin (Eds.), Coding processes in human memory. Washington, DC: Winston.

Glanzer, M. \& SchwarTZ, A. (1971). Mnemonic structure in free recall: Differential effects on STS and LTS. Journal of Verbal Learning and Verbal Behavior, 10, 194-198.

HASTIE, R. (1975). Intralist repetition in free recall: Effects of frequency attribute recall instructions. Journal of Experimental Psychology: Human Learning and Memory, 104, 3-12.

Hudson, R. L. \& AUstin, J. B. (1970). Effect of context and category name on the recall of categorized word lists. Journal of Experimental Psychology, 86, 43-47.

Hudson, R. L., \& Davis, J. L. (1972). The effect of intralist cues, extralist cues, and category names on categorized recall. Psychonomic Science, 29, 71-75.

Jenkins, J. J., Mink, W. D., \& Russell, W. A. (1958). Associative clustering as a function of verbal association strength. Psychological Reports, 4, 127-136.

JENKINS, J. J., \& RuSSELl, W. A. (1952). Associative clustering during recall. Journal of Abnormal and Social Psychology, 47, 818-821.

JoHNSON, N. F. (1970). The role of chunking and organization in the process of recall. In G. H. Bower (Ed.), The psychology of learning and motivation (Vol. 4). New York: Academic Press.

KARChMER, N. A., \& WinOGRAD, E. (1971). The effects of studying a subset of familiar items on recall of the remaining items: The John Brown effect. Psychonomic Science, 25, 224-225.

KINTSCH, W. (1970). Models for free recall and recognition. In D. A Norman (Ed.), Models of human memory. New York: Academic Press.

LAUER, P. A. (1974). Encoding specificity in the cued and free recall of categorically and alphabetically organized words. Bulletin of the Psychonomic Society, 4, 496-498.

LAUER, P. A., \& BatTig, W. F. (1972). Free recall of taxonomically and alphabetically organized word lists as a function of storage and retrieval cues. Journal of Verbal Learning and Verbal Behavior, 11, 333-342.

LEWIS, M. Q. (1971). Categorized lists and cued recall. Journal of Experimental Psychology, 87, 129-131.

LEWIS, M. Q. (1974). Cue effectiveness in cued recall. Journal of Experimental Psychology, 102, 737-739.

Luek, S. P., Mclaughlin, J. P., \& Cicala, G. A. (1971). Effects of blocking of input and blocking of retrieval cues on free recall learning. Journal of Experimental Psychology, 91, 159-161.

MANDLER, G. (1967). Organization and memory. In K. W. Spence \& J. T. Spence (Eds.) The psychology of learning and motivation (Vol. 1, pp 327-372). New York: Academic Press.

MARSHALL, G. R. (1967). Stimulus characteristics contributing to organization in free recall. Journal of Verbal Learning and Verbal Behavior, 6, 364-374.

Mathews, R. C., \& Tulving, E. (1973). Effects of three types of repetition on cued and noncued recall of words. Journal of Verbal Learning and Verbal Behavior, 12, 707-721.

MuelleR, C. W., \& WATKINS, M. J. (1977). Inhibition from part-set cuing: A cue-overload interpretation. Journal of Verbal Learning and Verbal Behavior, 16, 699-709.

MURDOCK, B. B. (1960). The immediate retention of unrelated words. Journal of Experimental Psychology, 60, 222-234.

NeELy, J. H., SChMidT, S. R., \&oediger, H. L., III. (1983). Inhibition from related primes in recognition memory. Journal of Experimental Psychology: Learning, Memory, and Cognition, 9, 196-211.

NELSON, D. L., \& MCEvoY, C. L. (1979a). Effects of retention interval and modality on sensory and semantic trace information Memory \& Cognition, 7, 257-262.

Nelson, D. L., \& McEvoy, C. L. (1979b). Encoding context and set size. Journal of Experimental Psychology: Human Learming and Memory, 5, 292-314.

Nelson, D. L., McEvoy, C. L., \& Friedrich, M. A. (1982). Extralist cuing and retrieval inhibition. Journal of Experimental Psychology: Learning, Memory, and Cognition, 8, 90-105.

Nickerson, R. S., Smith, E. E., \& Wallach, R. W. (1984). Memory search of semantic categories following exposure to category instances. Manuscript submitted for publication. 
Parker, R. E., \& Warren, L. (1974). Partial category cuing: The accessibility of categories. Journal of Experimental Psychology, 102, 1123-1125.

Pollio, H. R., \& Gerow, J. R. (1968). The role of rules in recall. American Journal of Psychology, 81, 303-313.

RaAiJMAKers, J. G. W., \& ShIFfrin, R. M. (1981). Search of associative memory. Psychological Review, 88, 93-134.

Reardon, E., Polzella, D., \& Brown, T. W. (1975). Re-examination of traced storage in free recall. Perceptual and Motor Skills, 41, 383-392.

RobBins, D., BraY, J. F., \& Irvin, J. R. (1974). Intralist contrast effects in cued recall. Journal of Experimental Psychology, 103, 150-155.

ROBERTS, W. A. (1972). Free recall of word lists varying in length and rate of presentation: A test of the total time hypothesis. Journal of Experimental Psychology, 92, 365-372.

ROEDIGER, H. L., III. (1973). Inhibition in recall from cueing with recall targets. Journal of Verbal Leaming and Verbal Behavior, 12, 644-657.

RoEDIGER, H. L., III. (1974). Inhibiting effects of recall. Memory \& Cognition, 2, 261-269.

RoEDIGER, H. L., III. (1978). Recall as a self-limiting process. Memory \& Cognition, 6, 54-63.

Roediger, H. L., III, Neely, J. H., \& Blaxton, T. A. (1983). Inhibition from related primes in semantic memory retrieval: A reappraisal of Brown's (1979) paradigm Journal of Experimental Psychology: Learning, Memory, and Cognition, 9, 478-485.

RoEdiger, H. L., III, \& SCHMIDT, S. R. (1980). Output interference in the recall of categorized and paired-associate lists. Journal of Experimental Psychology: Human Learning and Memory, 6, 91-105.

Roediger, H. L., III, Stellon, C. C., \& Tulving, E. (1977). Inhibition from part-list cues and rate of recall. Journal of Experimental Psychology: Human Learning and Memory, 3, 174-188.

Roediger, H. L., III, \& Tulving, E. (1974, May). Part list cuing and directed forgetting. Paper presented at the meeting of the Midwestern Psychological Association, Chicago.

RoEdiger, H. L., III, \& TulviNG, E. (1979). Exclusion of material from recall as a postretrieval operation. Journal of Verbal Learning and Verbal Behavior, 18, 601-615.

Rundus, D. (1973). Negative effects of using list items as recall cues. Journal of Verbal Learning and Verbal Behavior, 12, 43-50.

SEGAL, M. A., \& MANDLER, G. (1967). Directionality and organization processes in paired-associate learning. Journal of Experimental Psychology, 74, 305-312.

ShIFFRIN, R. M. (1970). Memory search. In D. A. Norman (Ed.), Models of human memory. New York: Academic Press.

SLAmeCKa, N. J. (1968). An examination of trace storage in free recall. Journal of Experimental Psychology, 76, 504-513.

SiameCKa, N. J. (1969). Testing for associative storage in multitrial free recall. Journal of Experimental Psychology, 81, 557-560.

SLAMECKA, N. J. (1972). The question of associative growth in the learn- ing of categorized materials. Journal of Verbal Learning and Verbal Behavior, 11, 324-332.

Slamecka, N. J. (1975). Intralist cueing of recognition. Journal of Verbal Learning and Verbal Behavior, 14, 630-637.

SMITH, A. D. (1971). Output interference and organized recall from long-term memory. Journal of Verbal Learning and Verbal Behavior, 10, 400-408.

SMrTH, A. D. (1973). Input order and output interference in organized recall. Journal of Experimental Psychology, 100, 147-150.

Smith, A. D., D'AGostino, P. R., \& ReID, L. (1970). Output interference in long-term memory. Canadian Journal of Psychology, 24, 85-87.

Todres, A. K., Watkins, M. J. (1981). A part-set cuing effect in recognition. Journal of Experimental Psychology: Human Learning and memory, 7, 91-99.

Tulving, E. (1964). Intratrial and intertrial retention: Notes towards a theory of free recall verbal learning. Psychological Review, 71, 219-237.

TULVING, E. (1968). Theoretical issues in free recall. In T. R. Dixon \& D. L. Horton (Eds.) Verbal behavior and general behavior theory. Englewood-Cliffs, NJ: Prentice-Hall

TUlving, E., \& ARBUCKLE, T. Y. (1963). Sources of intratrial interference in paired-associate learning. Journal of Verbal Learning and Verbal Behavior, 1, 321-33.

TUlving, E., \& HASTIE, R. (1972). Inhibition effects of intralist repetition in free recall. Journal of Experimental Psychology, 92, 297-304.

Tulving, E., \& Madigan, S. A. (1970). Memory and verbal learning. Annual Review of Psychology, 21, 437-484.

Tulving, E., \& Pearlstone, Z. (1966). Availability versus accessibility of information in memory for words. Journal of Verbal Learning and Verbal Behavior, 5, 381-391.

Tulving, E., \& PsotKA, J. (1971). Retroactive inhibition in free recall inaccessibility of information available in the memory store. Journal of Experimental Psychology, 87, 1-8.

WATKINS, M. J. (1975). Inhibition in recall with extralist "cues." Journal of Verbal Learning and Verbal Behavior, 14, 294-303.

WAUGH, N. C. (1963). Immediate memory as a function of repetition. Journal of Verbal Learning and Verbal Behavior, 2, 107-112.

WiCKelgREN, W. A. (1976). Network strength theory of storage and retrieval dynamics. Psychological Review, 83, 466-478.

Wood, D. (1969). Retrieval cues and the accessibility of higher-order memory units in multitrial free recall. Journal of Verbal Learning and Verbal Behavior, 8, 782-789.

\section{NOTE}

1. Following Cohen (1963), the convention has usually been adopted of saying that a category has been recalled if at least one instance of that category (other than an instance that has been used as a cue) has been recalled. That convention is used in this paper. 